\title{
Adeloneivaia schubarti Rêgo Barros \& Mielke e seus estágios imaturos (Lepidoptera, Saturniidae, Ceratocampinae)
}

\author{
Eurides Furtado ${ }^{1}$
}

\begin{abstract}
Adeloneivaia schubarti Rêgo Barros \& Mielke and its immature stages (Lepidoptera, Saturniidae, Ceratocampinae). Descriptions of the morphology and behavior of the immature stages of Adeloneivaia schubarti Rêgo Barros \& Mielke, 1970 are given for the first time. The larvae was reared (in captivity) on Stryphnodendron adstringens (Mart.) Coville (Leguminosae-Mimosoideae). Egg, larval instars, pupa and adults are illustrated in color and line drawings.

KEY WORDS. Lepidoptera, Saturniidae, Ceratocampinae, immature stages, Brazil
\end{abstract}

Quando entomologistas brasileiros estenderam suas áreas de estudo até os cerrados do Brasil central, lá encontraram muitas espécies de Saturniidae, e também de outras famílias, novas para a ciência. Nirton Tangerini foi um desses pioneiros, e entre outras, coletou em setembro de 1966 uma espécie nova do gênero Adeloneivaia Travassos, descrita por RÊGO BARROS \& MIELKE (1970) como A. schubarti. Hoje, sua distribuição espacial chega aos cerrados do Distrito Federal, Goiás, Minas Gerais, São Paulo (LEMAIRE 1988) e Mato Grosso até a zona de transição com as matas amazônicas, no alto Rio Arinos. Provavelmente deve ocorrer também, nos estados limítrofes, Tocantins e Mato Grosso do Sul.

Neste trabalho descreve-se pela primeira vez os estágios imaturos desta espécie. Imaturos e adultos são ilustrados a cores, e a traço (primeiro ínstar e pupa).

\section{MATERIAL E MÉTODOS}

Diversas possíveis plantas hospedeiras foram oferecidas às larvas, que imediatamente aceitaram Stryphnodendron adstringens (Mart.) Coville (Leguminosae-Mimosoideae). Parte das larvas foi criada em caixas plásticas no laboratório, e parte em viveiros de tela plástica, montados sobre ramagens vivas na planta hospedeira. Estas últimas tiveram um desenvolvimento melhor, foram mais saudáveis, e proporcionaram imagos com tamanho maior e melhor aparência, a maioria dos quais foi liberada na natureza com o objetivo de manter e ampliar o equilíbrio populacional da espécie.

\section{RESULTADOS}

Ovo (Fig. 1)

Elipsóide com as duas faces fortemente achatadas e com a área central côncava. Face maior verde-clara translúcida; a menor verde-amarelada. Comprimento: 2,2 mm; largura: 2,0 mm; espessura: 1,0 mm. Período embrionário: sete dias.

1) Caixa Postal 97, 78400-000 Diamantino, Mato Grosso, Brasil. 


\section{Larva}

Primeiro ínstar (Figs 2, 10). Cabeça arredondada com o vértice levemente deprimido, castanho-clara translúcida; peças bucais pouco mais escuras. Tórax com longos scoli subdorsais, sendo um no protórax, pouco mais curto que os seguintes; um par no mesotórax e um par no metatórax, todos castanho-avermelhado escuros, haste bifurcada, com minúsculas ramificações. Abdome com quatro séries de scoli com pequenas ramificações: os subespiraculares menores que os demais; os supraespiraculares pouco mais grossos e mais ramificados; os subdorsais e os dorsais ainda maiores; todos castanho-amarelados com a porção apical mais escura. Scolus dorsal A8 semelhante aos torácicos, mas pouco mais curto e mais grosso; scolus ímpar na linha dorsal de A9 pouco maior que os subdorsais. Pernas torácicas, abdominais e anais verde-amareladas. Escudo supranal triangular com chalazae laterais castanho-claras. Tegumento inicialmente amarelado; depois verde-folha com a área espiracular verde-amarelada; castanho-avermelhado nas áreas subdorsal e dorsal meso- e metatorácicas e na dorsal de A8-9, na base dos scoli. Comprimento ao eclodir: 5,0 mm; no final do ínstar: 10,0 mm. Duração: três dias.

Segundo ínstar (Fig. 3). Cabeça oblonga; verde-clara, com estreita faixa vertical amarelada, laterofrontal, com a borda posterior castanho-avermelhada; mandíbulas e antenas, castanho-claras. Scoli torácicos semelhantes ao ínstar anterior, neste ínstar com anelações amareladas no terço apical. Scoli ímpares em A8 e em A9 poucos mais longos que na idade anterior. Faixa espiracular amarela. Scoli subespiraculares castanho-avermelhados em A1, A3, A5, A7 e A8 e amarelos com a porção apical suja de castanho em A2, A4 e A6. Área mediana de T3, A2, A4, A6 e A8 protuberante da ruga espiracular à base dos scoli dorsais, e com a coloração amarela. Pernas torácicas castanho-avermelhadas; as abdominais e as anais, verdes com os escudos sujos de castanho-avermelhado. São verdes os scoli subdorsais e os dorsais A1, A3, A5 e A7. Tegumento predominantemente verde-folha, pouco mais claro na região dorsal, e castanho-avermelhado no dorso meso- e metatorácico. Comprimento: 15,0 mm. Duração: três dias.

Terceiro ínstar (Fig. 4). Assim difere do ínstar anterior: desaparecem os scoli subdorsais e a coloração castanho-avermelhada junto à faixa amarelada da cabeça; os scoli torácicos são mais claros e têm a haste pouco mais curta e mais grossa; a área mediana de T3, A2, A4, A6 e A8 têm a coloração amarelo-ouro mais forte; os scoli dorsais de A2, A4 e A6 são amarelo-ouro na borda externa e castanho-amarelados na interna; são amarelas as bordas laterais da placa supranal; desaparece a cor amarela da ruga espiracular em T1-2, A1, A3, A5, A7 e A9-10. Comprimento: 22,0 $\mathrm{mm}$. Duração: dois a quatro dias.

Quarto ínstar (Fig. 5). Cabeça como no ínstar anterior. Scoli protorácicos curtos, quase lisos, verde-amarelados com os ápices pretos; os meso- e os metatorácicos mais longos, haste com pequenos espinhos, castanho-avermelhados com a porção apical mais clara, o subdorsal metatorácico com bela coloração metálica prateada na borda externa; scoli supraespiraculares neste ínstar ausentes em A1, A3, A5 e A6, e como pequena verruga prateada em A2, A4, A6 e A8; scoli dorsais de A2, A4 e A6 espiniformes, haste com espinhos esparsos, castanho-avermelhados com a porção apical amarelada na borda interna e prateada na externa; scoli 

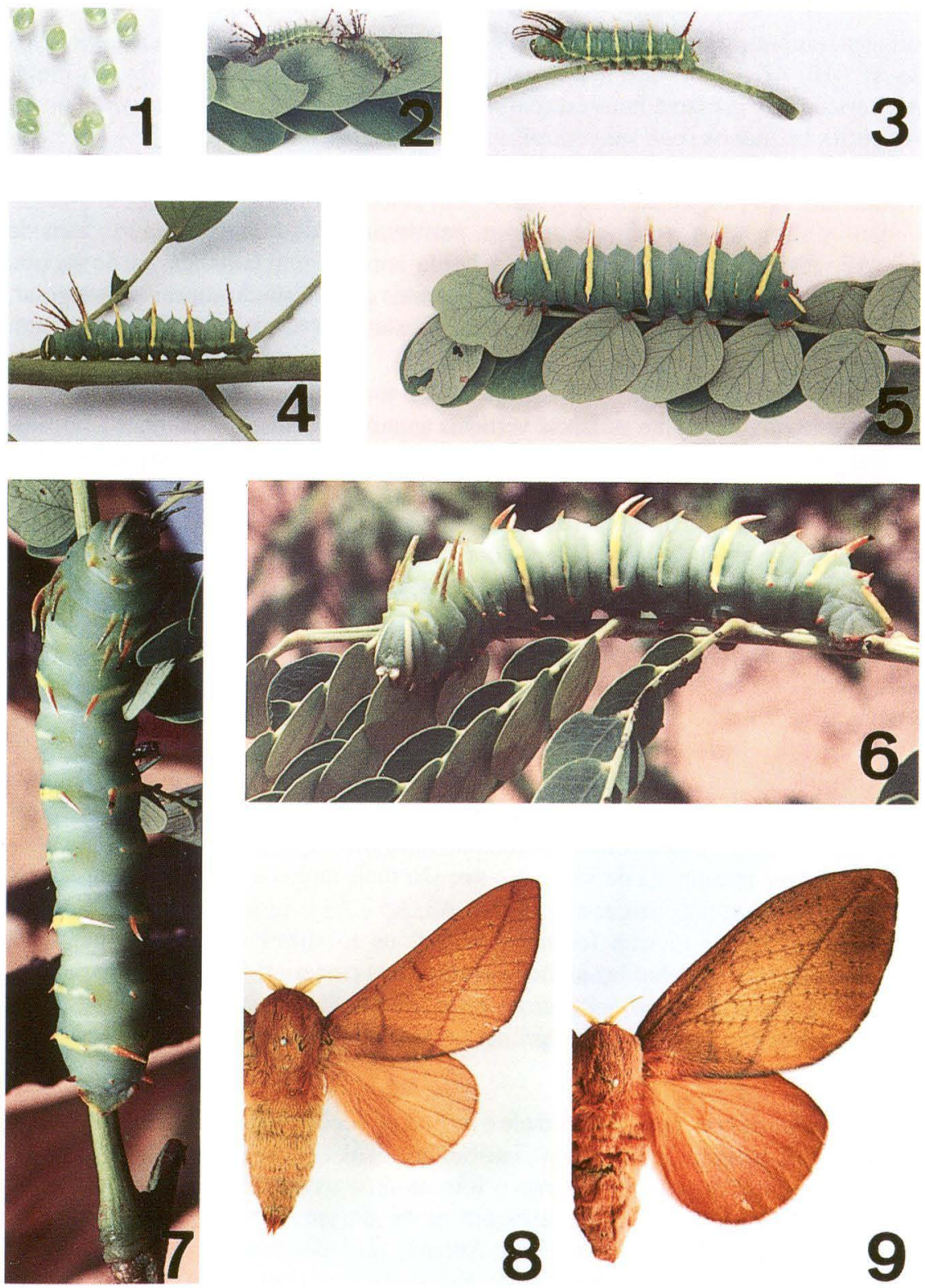

Figs 1-9. Adeloneivaia schubarti. (1) Ovos; (2) larvas de primeiro instar, vista laterodorsal; (3) larva de segundo instar, vista laterodorsal; (4) larva de terceiro instar, vista lateral; (5) larva de quarto instar, vista lateral; (6-7) larvas de quinto instar: (6) vista laterodorsal, (7) vista dorsal; (8-9) adultos, vista dorsal: (8) macho, margem costal $35 \mathrm{~mm}$; (9) fêmea, margem costal 41 $\mathrm{mm}$. 
subespiraculares pequenos, em forma de acúleos, castanho-avermelhados, sendo os de A2, A4, A6 e A8 pouco maiores e com a borda dorsal amarelada; scolus ímpar A8 pouco mais grosso e mais curto que os meso- e os metatorácicos; scolus ímpar A9 curto; pequenos scoli subventrais castanho-avermelhados em T1-3, A1-2 e A9. Pernas torácicas castanho-avermelhadas; as abdominais e as anais da mesma cor do tegumento, com os escudos mesclados com coloração castanho-avermelhada. Espiráculos elipsoidais, verde-amarelados, peritrema verde-escuro. Área mediana de T3, A2, A4, A6 e A8 amarela com a borda anterior parcialmente verde-escura. Tegumento verde-folha com a região dorsal mais clara. Escudo supranal triangular, com as bordas laterais amarelas e calosidade castanho-avermelhada. Comprimento: 35,0 mm. Duração: três dias.

Quinto ínstar (Figs 6-7). Cabeça com o mesmo formato anterior; coloração geral verde-olivácea, com as faixas verticais amareladas; área frontal micro-sulcada, suturas profundas, fronte deprimida; labro bem desenvolvido, projetado para a frente, verde mesclado de castanho; mandíbulas e ocelos, pretos. Scoli meso- e metatorácicos aproximadamente iguais, haste mais curta que no ínstar anterior, lisa, alaranjada com o terço apical parcialmente verde; scoli dorsais A2, A4 e A6 semelhantes e mais curtos que os torácicos, com a borda externa prateada; scolus A8 como estes últimos, porém mais grosso, com a porção apical preta; scoli dorsais A1, A3, A5, A7-8 e scolus ímpar A9, verde-amarelados com a porção apical alaranjada, pequenos, acúleos, inclinados para trás; scoli supraespiraculares pouco aparentes, algo maiores em A2, A4, A6 e A8, estes com leve brilho prateado; scoli subespiraculares A1-9 e subventrais T1-3, A1-2 e A9, curtos, em forma de acúleos, fulvos, inclinados para trás. Pernas torácicas castanho-claras, as abdominais e as anais, verdes com os escudos mesclados de castanho-claro. Tegumento verde-oliváceo, mais claro na área dorsal. As faixas medianas verticais têm a coloração amarela mais fraca que no ínstar anterior, com a borda anterior marginada de verde-escuro; são mais largas e com maior nitidez em A2, A4, A6 e A8; mais fracas em T3, A1, A3, A5 e A7 e ausentes em T1-2 e A9-10. Espiráculos com o mesmo formato anterior; os localizados nas faixas amarelas verticais são verdes na borda anterior e amarelos na posterior; os demais inteiramente verdes. Escudo supranal semelhante ao ínstar anterior, com a calosidade mais concentrada nos ângulos anteriores. Comprimento: 55,0 mm. Duração: 8-15 dias.

\section{Pupa (Fig. 11)}

Cabeça e tórax com calosidade e muitas projeções espiniformes. As maiores, em forma de acúleos, estão assim distribuídas: duas em cada lado no vértice; duas na cabeça, dispostas verticalmente e três na área axilar das asas. As projeções menores estão dispersas irregularmente na borda anterior do estojo das asas e lateralmente no meso- e no metanoto. Antenas estriadas transversalmente. Clípeo, labro e pernas com calosidade irregular. Estojo das asas com calosidade puntiforme. Bordas de cada segmento abdominal serrilhadas com projeções aculeadas, maiores gradativamente da área espiracular à dorsal e ausentes na área ventral, na borda posterior de A7-10. Cremaster sagitiforme, com a ponta bifurcada e levemente rugoso. Coloração geral castanho-escura brilhante, quase preta; segmentos abdominais pouco mais claros, avermelhados. Comprimento: $43,5 \mathrm{~mm}$; espessura: 11,0 mm. Período pupal: 30-61 dias. 

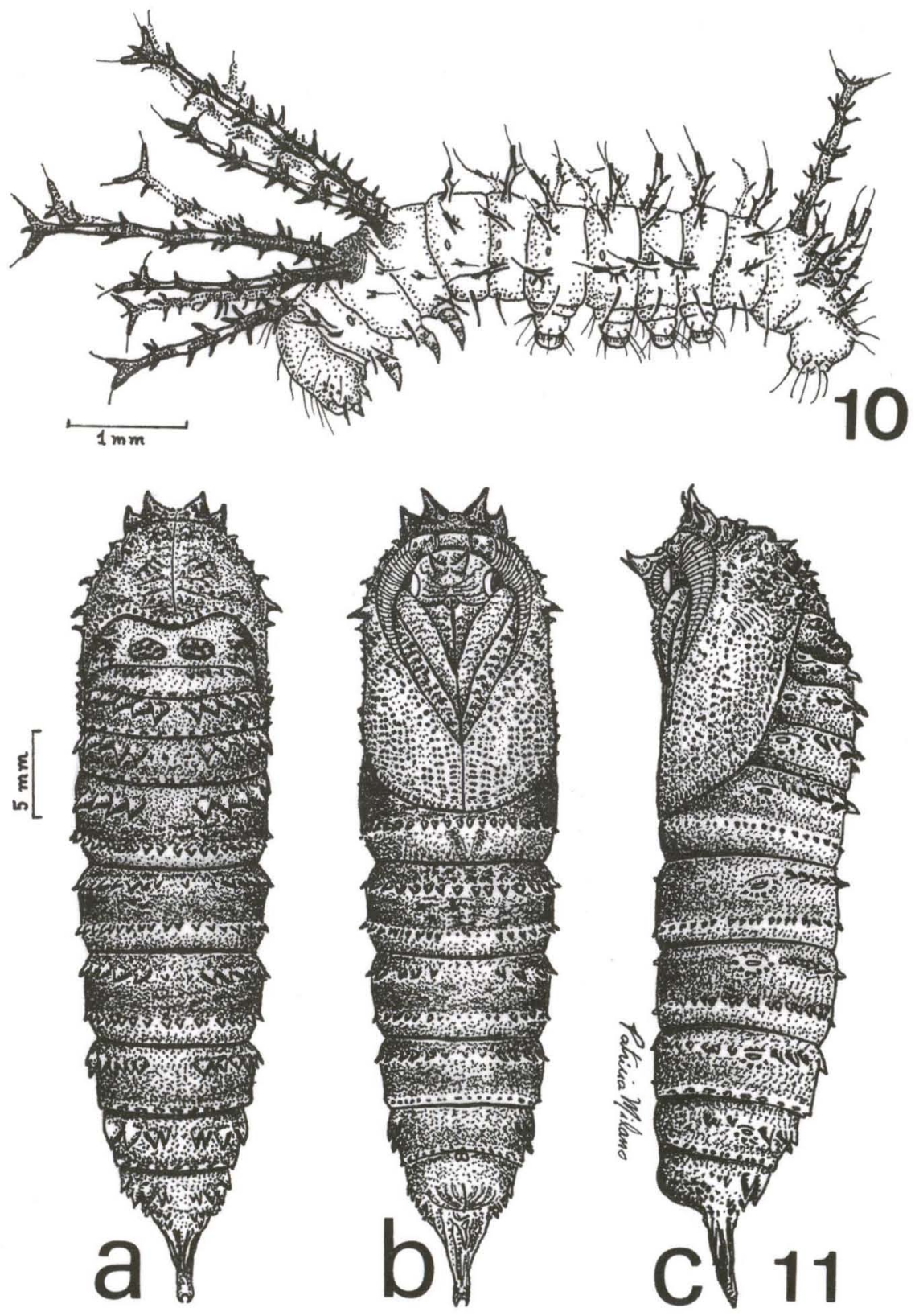

Figs 10-11. Adeloneivaia schubarti. (10) larva de primeiro instar, vista laterodorsal; (11) pupa: (a) vista dorsal, (b) vista ventral, (c) vista lateral. 


\section{Dados bionômicos}

Espécie univoltina, A. schubarti (Figs 8-9) aparece no início da estação das chuvas, com maior ocorrência em outubro. Os machos são mais freqüentes que as fêmeas, e ambos os sexos são atraídos por focos luminosos, sobretudo os de lâmpadas mistas e a vapor de mercúrio.

Neste estudo a postura foi de 59 ovos, mas poderia ser maior, já que a fêmea mater foi coletada depois de provavelmente já ter ovipositado na natureza. As larvas são solitárias em todos os ínstares, e como outras espécies de Ceratocampinae que vivem sobre Mimosoideae, são facilmente confundidas com os folíolos desta leguminosa, o que constitui eficaz camuflagem. Estágio pupal no solo. O ciclo evolutivo foi de 56-96 dias.

\section{DISCUSSÃO}

Ao estudar os estágios imaturos de Megaceresa pulchra (Bouvier) (FURTADO 1999) constatou-se a afinidade desta com espécies do gênero Adeloneivaia Travassos, 1940, contrariando MICHENER (1952) que o considera um subgênero de Adelowalkeria Travassos, 1941, enquanto que Travassos \& NORONHA (1967) o consideram um sinônimo.

Comparando-se o comportamento do adulto e os estágios imaturos de $M$. pulchra $\operatorname{com} A$. schubarti chega-se à segura conclusão de que são espécies congenéricas. Detalhes do ciclo evolutivo muitas vezes devem prevalecer à detalhes anatômicos, estes nem sempre conclusivos, e muitas vezes variáveis mesmo em indivíduos de uma mesma espécie.

AGRADECIMENTOS. À bióloga Patrícia Milano pelos desenhos e ao Prof. Gert Hatschbach, do Museu Botânico Municipal de Curitiba, Paraná, pela identificação da planta hospedeira.

\section{REFERÊNCIAS BIBLIOGRÁFICAS}

FuRTADO, E. 1999. Megaceresa pulchra (Bouvier) e seus estágios imaturos (Lepidoptera, Saturniidae, Ceratocampinae). Lambillionea 99 (4): 521-525.

Lemaire, C. 1988. Les Saturniidae Américans. III. Ceratocampinae. San José, Museo Nacional de Costa Rica, 480 pp.

Michener, C.D. 1952. The Saturniidae (Lepidoptera) of the Western Hemisphere. Morphology, phylogeny, and classification. Bull. Amer. Mus. Nat. Hist, New York, 98 (5): 335-502.

RÊGo Barros, A.R. \& O.H.H. MielKe. 1970. Um novo Adelocephalidae brasileiro (Lepidoptera). Atas Soc. Biol. Rio de Janeiro 16 (2-3): 91-96.

Travassos, L. \& D. Noronha. 1967. Novo arranjo sistemático de "Adelocephalidae" Burmeister, 1878 (Lepidoptera). Atas Soc. Biol. Rio de Janeiro 10 (6): 133-134.

Recebido em 04.V.2001; aceito em 22.X.2001. 